\title{
A linear fractional bilevel programming problem with multi- choice parameters
}

\author{
Ritu Arora ${ }^{1, \dagger}$ and Kavita Gupta ${ }^{2}$ \\ ${ }^{1}$ Department of Mathematics, Keshav Mahavidyalaya, University of Delhi, Delhi, India \\ E-mail: 〈rituarora@gmail.com〉 \\ ${ }^{2}$ Department of Mathematics, Kirori Mal College, University of Delhi, Delhi, India \\ E-mail: 〈gupta_kavita31@yahoo.com〉
}

\begin{abstract}
A bilevel programming problem (BLPP) is a hierarchical optimization problem where the constraint region of the upper level is implicitly determined by the lower level optimization problem. In this paper, a bilevel programming problem is considered in which the objective functions are linear fractional and the feasible region is a convex polyhedron. Linear fractional objectives in BLPP are useful in production planning, financial planning, corporate planning and so forth. Here, the cost coefficient of the objective functions are multi-choice parameters. The multi-choice parameters are replaced using interpolating polynomials. Then, fuzzy programming is used to find a compromise solution of the transformed BLPP. An algorithm is developed to find a compromise solution of BLPP. The method is illustrated with the help of an example.
\end{abstract}

Keywords: bilevel programming, linear fractional programming problem, fuzzy programming, compromise solution, multi-choice parameters

Received: June 28, 2016; accepted: August 14, 2017; available online: November 30, 2017

DOI: $10.17535 /$ crorr. 2017.0032

\section{Introduction}

The bilevel programming structure is a class of hierarchical problem that shows a two stage decision making process when the constrained region of the first level problem is implicitly determined by another optimization problem [3].

BLPP has been used by researchers in several fields ranging from economics to transportation engineering. BLPP is also used to model problems involving multiple decision makers. These include traffic signal optimization [17], structural design [19] and genetic algorithms [8].

Most of the extreme point algorithms are applied to the solution of a linear BLPP. Every linear bilevel programming problem with a finite optimal solution shares an important property where the optimal solution is attained at an extreme point

\footnotetext{
${ }^{\dagger}$ Corresponding author
} 
of the constraint region. This result was first established by W. Candler and R. Townsley [9]. Afterwards, W. Bialas and M. Karwan [7] proved it to be true under the assumption that the constraint region is bounded.

\section{Theoretical background}

Bilevel linear fractional programming problems are used to represent various decision making situations. Indices such as inventory/sales, output/employees, profit/cost are important in evaluating economic activities. Therefore, models that can effectively handle such fractional objectives are preferred.

The linear fractional bilevel programming problem is mathematically stated as (BLFPP) [4]:

where $\mathrm{X}_{2}$ solves

$$
\operatorname{Max}_{X_{1}} f_{1}\left(X_{1}, X_{2}\right)=\frac{c_{11} X_{1}+c_{12} X_{2}+\alpha_{1}}{d_{11} X_{1}+d_{12} X_{2}+\beta_{1}}
$$

subject to

$$
\operatorname{Max}_{X_{2}} f_{2}\left(X_{1}, X_{2}\right)=\frac{c_{21} X_{1}+c_{22} X_{2}+\alpha_{2}}{d_{21} X_{1}+d_{22} X_{2}+\beta_{2}}
$$

$$
\begin{gathered}
\mathrm{A}_{1} \mathrm{X}_{1}+\mathrm{A}_{2} \mathrm{X}_{2}=\mathrm{b} \\
\mathrm{X}_{1} \in \mathrm{R}^{\mathrm{n}_{1}}, \mathrm{X}_{2} \in \mathrm{R}^{\mathrm{n}_{2}} \\
\mathrm{c}_{11}^{\mathrm{T}}, \mathrm{d}_{11}^{\mathrm{T}}, \mathrm{c}_{21}^{\mathrm{T}}, \mathrm{d}_{21}^{\mathrm{T}} \in \mathrm{R}^{\mathrm{n}_{1}} ; \mathrm{c}_{12}^{\mathrm{T}}, \mathrm{d}_{12}^{\mathrm{T}}, \mathrm{c}_{22}^{\mathrm{T}}, \mathrm{d}_{22}^{\mathrm{T}} \in \mathrm{R}^{\mathrm{n}_{2}} \\
\mathrm{~A}_{1} \in \mathrm{R}^{\mathrm{m} \times \mathrm{n}_{1}}, \mathrm{~A}_{2} \in \mathrm{R}^{\mathrm{m} \times \mathrm{n}_{2}}, \mathrm{~b} \in \mathrm{R}^{\mathrm{m}} \text { and } \alpha_{1}, \alpha_{2}, \beta_{1}, \beta_{2} \in \mathrm{R}
\end{gathered}
$$

Here,

$$
\left(\mathrm{d}_{11} \mathrm{X}_{1}+\mathrm{d}_{12} \mathrm{X}_{2}+\beta_{1}\right)>0 \text { and }\left(\mathrm{d}_{21} \mathrm{X}_{1}+\mathrm{d}_{22} \mathrm{X}_{2}+\beta_{2}\right)>0 \forall\left(\mathrm{X}_{1}, \mathrm{X}_{2}\right) \in \mathrm{S}
$$

where

$$
\mathrm{S}=\left\{\left(\mathrm{X}_{1}, \mathrm{X}_{2}\right): \mathrm{A}_{1} \mathrm{X}_{1}+\mathrm{A}_{2} \mathrm{X}_{2}=\mathrm{b}\right\}
$$

Here, $\mathrm{S}$ is non-empty and compact.

In the bilevel linear fractional programming problem defined above, each of the objective functions at both the levels are linear fractional. Therefore, they are both pseudoconcave and pseudoconvex, and thus its optimal solution will be at an extreme point of $\mathrm{S}$.

The concept of fuzzy mathematical programming at a general level was introduced by Tanaka et al. [18] in the framework of fuzzy decision of Bellman and Zadeh [6]. Thereafter, the fuzzy programming approach to linear programming with seve- 
ral objectives was introduced by Zimmermann in 1978 [20]. In the recent past, Mohamed [15] investigated some new fuzzy programming forms by using the concept of a conventional goal programming approach which was further studied by Pal and Moitra [16]. Lee and Shih [11] proposed an interactive fuzzy approach to multilevel decision making problems. Mahmoud [1] in 2001 developed a fuzzy max-min decision model for solving the bilevel non-linear multiple objective decision making problem.

The multi-choice programming problem (MCPP) belongs to the non-convex mathematical programming problem. MCPP was originally devised by Healy Jr. in 1964. MCPP has many applications in decision making problems in the field of integer programming and combinatorics [14]. S. Acharya and M.P. Biswal [2] in 2015 presented a case study of a garment manufacture company demonstrating the application of MCPP. Chin Nung Liao et al. [12] applied multi-choice model to the management system.

In this paper, a linear fractional bilevel programming problem with multi choice parameters, BLFMCP is considered. The objective functions at both levels have multi-choice cost coefficients. The concept of interpolating polynomials is used which converts BLFMCP to a mixed integer quadratic fractional programming problem, BPPLIP. A fuzzy programming algorithm is proposed to find a solution which satisfies both decision makers of BPPLIP. Chang in 2008 [10] and Liao in 2009 [13] introduced different solution procedures to reduce the problem with multi-choice parameters to a mixed integer programming problem.

\section{Methodology to solve a multi-choice programming problem}

In a multi-choice programming problem, multiple choices for a parameter are available to the decision makers. This model utilizes appropriate resource from a given set of multiple resources. In this paper, we deal with the objective functions which have multi-choice cost coefficients at both levels. For this, we use interpolating polynomials. By applying this method, the problem with multichoice parameters is reduced to a mixed integer programming problem. Then, fuzzy programming is applied to find the compromise solution which satisfies both the decision makers. 


\subsection{Mathematical formulation}

Mathematically, a bilevel linear fractional programming problem with multi-choice parameters is defined as

$$
\begin{gathered}
(B L F M C P): \operatorname{Max}_{\mathrm{X}_{1}} \mathrm{Z}_{1}(X)=\frac{\left(\mathrm{c}_{1}^{(1)}, \mathrm{c}_{1}^{(2)}, \ldots, \mathrm{c}_{1}^{\left(\mathrm{t}_{1}\right)}\right)}{\left(\mathrm{d}_{1}^{(1)}, \mathrm{d}_{1}^{(2)}, \ldots, \mathrm{d}_{1}^{\left(\mathrm{t}_{1}\right)}\right)} \mathrm{x}_{1}+\frac{\left(\mathrm{c}_{2}^{(1)}, \mathrm{c}_{2}^{(2)}, \ldots, \mathrm{c}_{2}^{\left(\mathrm{t}_{2}\right)}\right)}{\left(\mathrm{d}_{2}^{(1)}, \mathrm{d}_{2}^{(2)}, \ldots, \mathrm{d}_{2}^{\left(\mathrm{t}_{2}\right)}\right)} \mathrm{x}_{2}+\ldots . \\
\frac{\left(\mathrm{c}_{\mathrm{n}}^{(1)}, \mathrm{c}_{\mathrm{n}}^{(2)}, \ldots, \mathrm{c}_{\mathrm{n}}^{\left(\mathrm{t}_{\mathrm{n}}\right)}\right)}{\left(\mathrm{d}_{\mathrm{n}}^{(1)}, \mathrm{d}_{\mathrm{n}}^{(2)}, \ldots, \mathrm{d}_{\mathrm{n}}^{\left(\mathrm{t}_{\mathrm{n}}\right)}\right)} \mathrm{x}_{\mathrm{n}} \\
\operatorname{Max}_{\mathrm{X}_{2}} \mathrm{Z}_{2}(\mathrm{X})=\frac{\left(\mathrm{p}_{1}^{(1)}, \mathrm{p}_{1}^{(2)}, \ldots, \mathrm{p}_{1}^{\left(\mathrm{s}_{1}\right)}\right)}{\left(\mathrm{q}_{1}^{(1)}, \mathrm{q}_{1}^{(2)}, \ldots, \mathrm{q}_{1}^{\left(\mathrm{s}_{1}\right)}\right)} \mathrm{x}_{1}+\frac{\left(\mathrm{p}_{2}^{(1)}, \mathrm{p}_{2}^{(2)}, \ldots, \mathrm{p}_{2}^{\left(\mathrm{s}_{2}\right)}\right)}{\left(\mathrm{q}_{2}^{(1)}, \mathrm{q}_{2}^{(2)}, \ldots ., \mathrm{q}_{2}^{\left(\mathrm{s}_{2}\right)}\right)} \mathrm{x}_{2}+\ldots . . \\
\frac{\left(\mathrm{p}_{\mathrm{n}}^{(1)}, \mathrm{p}_{\mathrm{n}}^{(2)}, \ldots, \mathrm{p}_{\mathrm{n}}^{\left(\mathrm{s}_{\mathrm{n}}\right)}\right)}{\left(\mathrm{q}_{\mathrm{n}}^{(1)}, \mathrm{q}_{\mathrm{n}}^{(2)}, \ldots, \mathrm{q}_{\mathrm{n}}^{\left(\mathrm{s}_{\mathrm{n}}\right)}\right)} \mathrm{x}_{\mathrm{n}}, \text { for a given } \mathrm{X}_{1}
\end{gathered}
$$

where $\mathrm{X}=\left(\mathrm{X}_{1}, \mathrm{X}_{2}\right)=\left(\mathrm{x}_{1}, \ldots, \mathrm{x}_{\mathrm{n}}\right) \in \mathrm{S}^{*}$.

Here, $\mathrm{S}^{*}=\{\mathrm{X} \mid \mathrm{AX}=\mathrm{b}\}$ is non-empty and bounded.

We have, $t_{j}(j=1, \ldots, n)$ are multi-choices for the jth parameters $c_{j}$ and $d_{j}$.

Also, $\mathrm{s}_{\mathrm{k}}(\mathrm{k}=1 ., \ldots \mathrm{n})$ are the choices for the $\mathrm{k}$-th parameters $\mathrm{p}_{\mathrm{k}}$ and $\mathrm{q}_{\mathrm{k}}$. Also,

$$
\begin{gathered}
\left(\mathrm{d}_{\mathrm{j}}^{(1)}, \mathrm{d}_{\mathrm{j}}^{(2)}, \ldots, \mathrm{d}_{\mathrm{j}}^{\left(\mathrm{t}_{\mathrm{j}}\right)}\right)>0 \forall \mathrm{X} \in \mathrm{S}^{*} ; \mathrm{j}=1, \ldots \mathrm{n} . \\
\left(\mathrm{q}_{\mathrm{k}}^{(1)}, \mathrm{q}_{\mathrm{k}}^{(2)}, \ldots, \mathrm{q}_{\mathrm{k}}^{\left(\mathrm{s}_{\mathrm{k}}\right)}\right)>0 \forall \mathrm{X} \in \mathrm{S}^{*} ; \mathrm{k}=1, \ldots \mathrm{n} . \\
\quad \mathrm{X} \in \mathrm{R}^{\mathrm{n}}, \mathrm{A} \in \mathrm{R}^{\mathrm{m} \times \mathrm{n}}, \mathrm{b} \in \mathrm{R}^{\mathrm{m} \times 1} \\
\mathrm{c}_{\mathrm{i}}^{\mathrm{j}}, \mathrm{d}_{\mathrm{i}}^{\mathrm{j}}\left(\mathrm{i}=1, \ldots, \mathrm{n}, \mathrm{j}=1, \ldots, \mathrm{t}_{\mathrm{i}}\right) \in \mathrm{R} \\
\mathrm{p}_{\mathrm{k}}^{1}, \mathrm{q}_{\mathrm{k}}^{1}\left(\mathrm{k}=1, \ldots . \mathrm{n}, 1=1, \ldots, \mathrm{s}_{\mathrm{k}}\right) \in \mathrm{R}
\end{gathered}
$$

\subsection{Solution procedure for BLFMCP}

To solve BLFMCP, we use interpolating polynomials [5].

\subsubsection{Interpolating a polynomial of degree $n$}

In order to find a polynomial $\mathrm{P}_{\mathrm{n}}(\mathrm{x})$ for which $\operatorname{deg}\left(\mathrm{P}_{\mathrm{n}}\right) \leq \mathrm{n}$, passing through the data points $\left(\mathrm{x}_{0}, \mathrm{y}_{0}\right),\left(\mathrm{x}_{1}, \mathrm{y}_{1}\right), \ldots,\left(\mathrm{x}_{\mathrm{n}}, \mathrm{y}_{\mathrm{n}}\right)$, the solution is given by Lagrange's formula, 
where

$$
\begin{aligned}
& \mathrm{P}_{\mathrm{n}}(\mathrm{x})=\mathrm{y}_{0} \mathrm{~L}_{0}(\mathrm{x})+\mathrm{y}_{1} \mathrm{~L}_{1}(\mathrm{x})+\ldots .+\mathrm{y}_{\mathrm{n}} \mathrm{L}_{\mathrm{n}}(\mathrm{x}) \\
& \mathrm{L}_{\mathrm{k}}(\mathrm{x})=\prod_{\mathrm{i} \neq \mathrm{k}}\left(\frac{\mathrm{x}-\mathrm{x}_{\mathrm{i}}}{\mathrm{x}_{\mathrm{k}}-\mathrm{x}_{\mathrm{i}}}\right), \quad \mathrm{k}=0,1, \ldots, \mathrm{n} ; \mathrm{i}=0,1 \ldots, \mathrm{n}
\end{aligned}
$$

Here, in this formula, each such function is a polynomial of degree n. Also,

$$
\mathrm{L}_{\mathrm{k}}\left(\mathrm{x}_{\mathrm{i}}\right)= \begin{cases}1, & \mathrm{i}=\mathrm{k} \\ 0, & \mathrm{i} \neq \mathrm{k}\end{cases}
$$

Using these properties, it follows that the formula

$$
\mathrm{P}_{\mathrm{n}}(\mathrm{x})=\mathrm{y}_{0} \mathrm{~L}_{0}(\mathrm{x})+\mathrm{y}_{1} \mathrm{~L}_{1}(\mathrm{x})+\ldots .+\mathrm{y}_{\mathrm{n}} \mathrm{L}_{\mathrm{n}}(\mathrm{x})
$$

satisfies the interpolating problem for finding a solution to

$$
\operatorname{deg}\left(P_{n}\right) \leq n \text { and } P_{n}\left(x_{i}\right)=y_{i} ; i=0,1, \ldots, n .
$$

\subsubsection{Interpolating polynomial for the problem BLFMCP}

Consider the problem BLFMCP with objective functions having multi-choice cost coefficients at both levels. In order to deal with the multi-choice parameters $c_{j}(j$ $=1, \ldots . n)$ in the numerator at the upper level, we use Lagrange interpolation. For this, we introduce an integer variable $w_{j}$ which takes a $t_{j}$ number of values $\left(\mathrm{w}_{\mathrm{j}}=0,1, \ldots, \mathrm{t}_{\mathrm{j}}-1\right)$. We formulate a Lagrange interpolating polynomial $\mathrm{f}_{\mathrm{c}_{\mathrm{j}}}\left(\mathrm{w}_{\mathrm{j}}\right)$ which passes through all the $t_{\mathrm{j}}$ number of points, as

$$
\begin{aligned}
f_{c_{j}}\left(w_{j}\right) & =\frac{\left(w_{j}-1\right)\left(w_{j}-2\right) \ldots .\left(w_{j}-t_{j}+1\right)}{(-1)^{t_{j}-1}\left(t_{j}-1\right) !} c_{j}^{(1)}+\frac{w_{j}\left(w_{j}-2\right) \ldots .\left(w_{j}-t_{j}+1\right)}{(-1)^{t_{j}-2}\left(t_{j}-2\right) !} c_{j}^{(2)}+ \\
& \frac{w_{j}\left(w_{j}-1\right) \ldots .\left(w_{j}-t_{j}+1\right)}{(-1)^{t_{j}-3} 2 !\left(t_{j}-3\right) !} c_{j}^{(3)}+\ldots . .+\frac{w_{j}\left(w_{j}-1\right)\left(w_{j}-2\right) \ldots .\left(w_{j}-t_{j}+2\right)}{\left(t_{j}-1\right) !} c_{j}^{\left(t_{j}\right)}, j=1,2, \ldots n
\end{aligned}
$$

Similarly, we deal with the multi-choice parameter $d_{j}(j=1, \ldots n)$ in the denominator at the upper level. Upon introducing an integer variable $\mathrm{v}_{\mathrm{j}}$ which takes $\mathrm{t}_{\mathrm{j}}$ number of values $\left(\mathrm{v}_{\mathrm{j}}=0,1, \ldots, \mathrm{t}_{\mathrm{j}}-1\right)$, we get a Lagrange interpolating polynomial $f_{d_{j}}\left(v_{j}\right)$ which passes through all the $t_{j}$ number of points, and we get 


$$
\begin{aligned}
f_{d_{j}}\left(v_{j}\right) & =\frac{\left(v_{j}-1\right)\left(v_{j}-2\right) \ldots .\left(v_{j}-t_{j}+1\right)}{(-1)^{t_{j}-1}\left(t_{j}-1\right) !} d_{j}^{(1)}+\frac{v_{j}\left(v_{j}-2\right) \ldots .\left(v_{j}-t_{j}+1\right)}{(-1)^{t_{j}-2}\left(t_{j}-2\right) !} d_{j}^{(2)} \\
& +\frac{v_{j}\left(v_{j}-1\right) \ldots .\left(v_{j}-t_{j}+1\right)}{(-1)^{t_{j}-3} 2 !\left(t_{j}-3\right) !} d_{j}^{(3)}+\ldots .+\frac{v_{j}\left(v_{j}-1\right) \ldots .\left(v_{j}-t_{j}+2\right)}{\left(t_{j}-1\right) !} d_{j}^{\left(t_{j}\right)}, j=1,2, \ldots . n .
\end{aligned}
$$

Similarly, for the lower level problem $Z_{2}(X)$, introducing the integer variables $Z_{j}$ and $\mathrm{y}_{\mathrm{j}}$ which take $\mathrm{s}_{\mathrm{j}}$ number of values $\left(\mathrm{z}_{\mathrm{j}}=0,1, \ldots, \mathrm{s}_{\mathrm{j}}-1\right)$ and $\left(\mathrm{y}_{\mathrm{j}}=0,1, \ldots, \mathrm{s}_{\mathrm{j}}-1\right)$ respectively, we can define the Lagrange interpolating polynomial, $\mathrm{f}_{\mathrm{p}_{\mathrm{j}}}\left(\mathrm{z}_{\mathrm{j}}\right)$ and $\mathrm{f}_{\mathrm{q}_{\mathrm{j}}}\left(\mathrm{y}_{\mathrm{j}}\right)$ respectively.

Introducing interpolating polynomials in the numerator and denominator of the problem BLFMCP is reduced to the mixed integer quadratic fractional programming problem (BPPLIP), defined as

(BPPLIP):

$$
\operatorname{Max}_{\mathrm{X}_{1}} Z_{1}(X)=\sum_{j=1}^{n}\left(\frac{f_{c_{j}}\left(w_{j}\right)}{f_{d_{j}}\left(v_{j}\right)}\right) x_{j}
$$

$$
\underset{X_{2}}{\operatorname{Max}} Z_{2}(X)=\sum_{j=1}^{n}\left(\frac{f_{p_{j}}\left(z_{j}\right)}{f_{q_{j}}\left(y_{j}\right)}\right) x_{j} \text {, for a given } X_{1} \text {. }
$$

where $X \in S^{*}, S^{*}=\{X \mid A X=b\}$. Also,

$$
\begin{array}{rc}
0 \leq \mathrm{w}_{\mathrm{j}} \leq \mathrm{t}_{\mathrm{j}}-1, & 0 \leq \mathrm{v}_{\mathrm{j}} \leq \mathrm{t}_{\mathrm{j}}-1 \\
0 \leq \mathrm{y}_{\mathrm{j}} \leq \mathrm{s}_{\mathrm{j}}-1, & 0 \leq \mathrm{z}_{\mathrm{j}} \leq \mathrm{s}_{\mathrm{j}}-1 \\
\mathrm{w}_{\mathrm{j}}, \mathrm{z}_{\mathrm{j}} \in \mathrm{Z}^{+} \cup\{0\}, \mathrm{j}=1, \ldots . \mathrm{n} ; & \mathrm{v}_{\mathrm{j}}, \mathrm{y}_{\mathrm{j}} \in \mathrm{Z}^{+}, \mathrm{j}=1, \ldots . \mathrm{n} .
\end{array}
$$

We want to find the solution of the above problem which satisfies both the decision makers. For this we need to find a compromise solution which can be obtained using fuzzy programming approach.

\subsection{Fuzzy programming approach to linear fractional bilevel programming problem}

Consider the problem BLFMCP. In order to apply fuzzy programming to $\mathrm{BLFMCP}$, construct the fuzzy membership functions. Solve $\mathrm{Z}_{1}(\mathrm{X})$ subject to the constraint (2). Let its individual best and worst solution be $Z_{1}^{\mathrm{b}}$ and $Z_{1}^{\mathrm{w}}$ respect- 
tively. This data can be used to define the membership function for the upper level problem.

$$
\mu\left(Z_{1}(X)\right)=\left\{\begin{array}{ccc}
1 & , & Z_{1}(X)>Z_{1}^{b} \\
\frac{Z_{1}(X)-Z_{1}^{w}}{Z_{1}^{\mathrm{b}}-Z_{1}^{\mathrm{w}}} & , & Z_{1}^{\mathrm{w}} \leq \mathrm{Z}_{1}(X) \leq Z_{1}^{\mathrm{b}} \\
0 & , & Z_{1}(X)<Z_{1}^{\mathrm{w}}
\end{array}\right.
$$

Let $\lambda_{1}$ be the minimum acceptable degree of satisfaction for the upper level problem $\mathrm{Z}_{1}(\mathrm{X})$. Again, let $\mathrm{Z}_{2}^{\mathrm{b}}$ and $\mathrm{Z}_{2}^{\mathrm{w}}$ be the best and worst solutions of $\mathrm{Z}_{2}(\mathrm{X})$.

Define the membership function for $\mathrm{Z}_{2}(\mathrm{X})$ as

$$
\mu\left(Z_{2}(X)\right)=\left\{\begin{array}{ccc}
1 & , & Z_{2}(X)>Z_{2}^{b} \\
\frac{Z_{2}(X)-Z_{2}^{w}}{Z_{2}^{\mathrm{b}}-Z_{2}^{\mathrm{w}}} & , & Z_{2}^{\mathrm{w}} \leq Z_{2}(X) \leq Z_{2}^{\mathrm{b}} \\
0 & , & Z_{2}(X)<Z_{2}^{\mathrm{w}}
\end{array}\right.
$$

Let $\lambda_{2}$ be the minimum acceptable degree of satisfaction for the lower level problem $\mathrm{Z}_{2}(\mathrm{X})$.The solutions so obtained after solving the upper level and lower level problems are different since the objective function at both the levels are conflicting in nature. Since the leader controls the decision variable $\mathrm{X}_{1}$, therefore to get the compromise solution for both the decision makers at two levels, the leader has to give the range for $\mathrm{X}_{1}$. Let $\mathrm{t}_{1}$ and $\mathrm{t}_{2}$ be the maximum and minimum tolerance limits for $\mathrm{X}_{1}$. Define the membership function for $\mathrm{X}_{1}$ as

$$
\mu\left(X_{1}\right)= \begin{cases}\frac{X_{1}-\left(X_{1}^{F}-t_{2}\right)}{t_{2}}, & X_{1}^{F}-t_{2} \leq X_{1} \leq X_{1}^{F} \\ \frac{\left(X_{1}^{F}+t_{1}\right)-X_{1}}{t_{1}}, & X_{1}^{F} \leq X_{1} \leq X_{1}^{F}+t_{1}\end{cases}
$$

Let $\lambda_{3}$ be the minimum acceptable degree of satisfaction of the decision variable $\mathrm{X}_{1}$.

Let $\delta=\min \left(\lambda_{1}, \lambda_{2}, \lambda_{3}\right)$. 
In order to generate the satisfactory solution for the problem BLFMCP which is also a pareto optimal solution with overall satisfaction for all decision-makers, solve the following Fuzzy Programming Problem (FPBLFPP) defined as

$$
\begin{gathered}
\operatorname{Max} \delta \\
\text { subject } \text { to } \mu\left(Z_{1}(X)\right) \geq \delta \\
\mu\left(Z_{2}(X)\right) \geq \delta \\
\mu\left(X_{1}\right) \geq \delta \\
X \in S^{*} . \\
0 \leq w_{j} \leq t_{j}-1 ; \quad 0 \leq v_{j} \leq t_{j}-1, \quad j=1, \ldots, n \\
0 \leq y_{j} \leq s_{j}-1 ; \quad 0 \leq z_{j} \leq s_{j}-1, \quad j=1, \ldots . n . \\
\mathrm{w}_{j}, z_{j} \in Z^{+} \cup\{0\}, \quad j=1, \ldots, n ; \quad v_{j}, y_{j} \in Z^{+}, j=1, \ldots, n ; \delta \in[0,1] .
\end{gathered}
$$

\section{A methodology to solve linear fractional bilevel program- ming problem with multi-choice parameters (BLFMCP)}

Consider a bilevel linear fractional programming problem with multi-choice parameters, BLFMCP. In this problem, the cost coefficients of the objective functions at both levels are multi-choice. In order to solve BLFMCP, the objective functions at both levels are dealt using interpolating polynomials. Using Lagranges interpolation, the BLFMCP problem is converted to a mixed integer quadratic fractional programming problem, BPPLIP. The transformed BPPLIP problem is solved using a fuzzy programming approach. For this we need to construct membership functions of the objective functions at both levels, that is, for $\mathrm{Z}_{1}(\mathrm{X})$ and $\mathrm{Z}_{2}(\mathrm{X})$ The membership function is also defined for the variables controlled by the leader. By constructing membership functions, the fuzzy programming problem FPBLFPP is formulated. The FPBLFPP problem is solved to obtain a satisfactory solution for BLFMCP. The algorithmic approach is described in Figure 1.

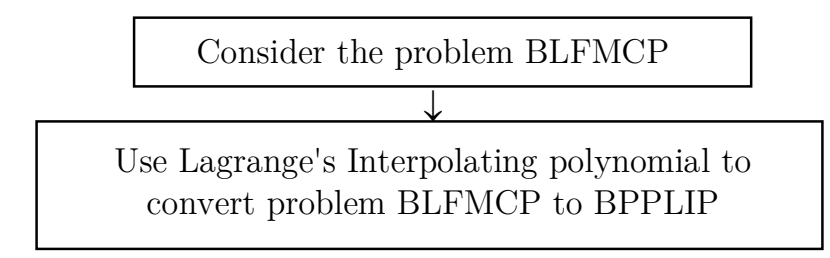




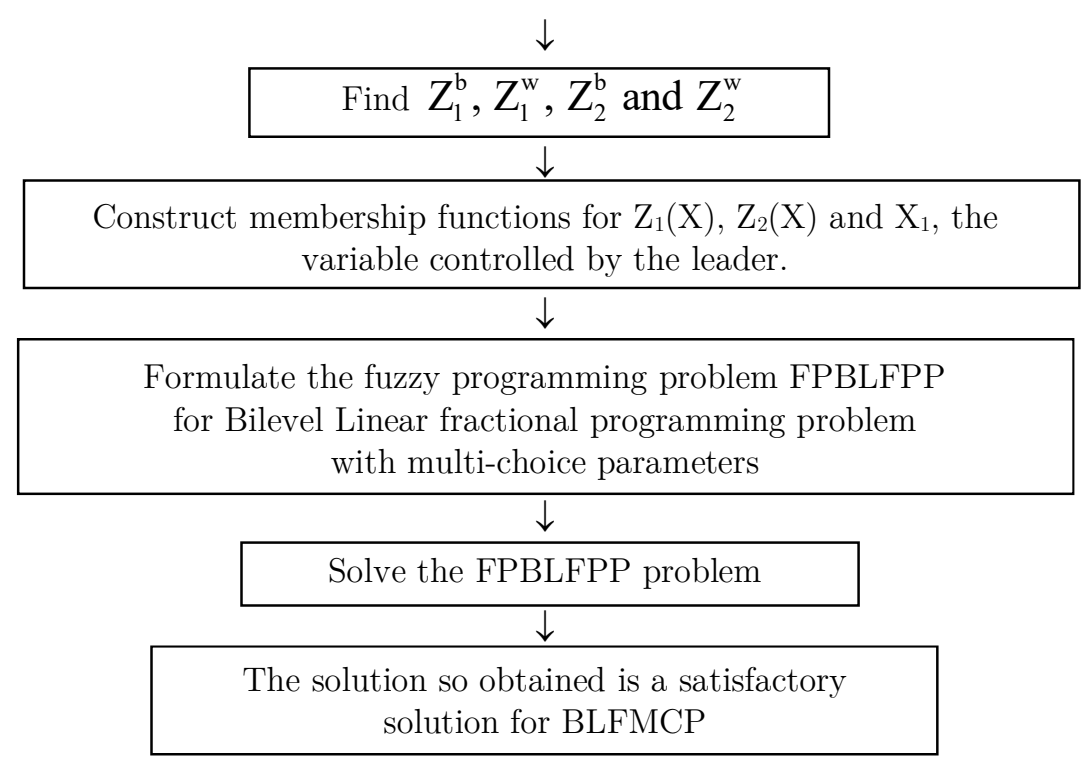

Figure 1: Algorithm for solving Linear Fractional Bilevel Programming Problem with Multi-choice Parameters

\section{An illustrative example}

A company manufactures three products A, B and C. It transports the products to different markets, $\mathrm{M}_{1}, \mathrm{M}_{2}, \mathrm{M}_{3}$ and $\mathrm{M}_{4}$. The production cost consists of the material cost, labour cost, storage, transportation etc. The company aims to invest in one product on a single market. For this, the company wants to find out its profit/cost ratio and output/employee ratio for an individual product. During production, the company has the following requirements for running its production cycle.

\begin{tabular}{|l|c|c|c|c|}
\hline Requirements & A & B & C & Availability \\
\hline Material 1 & 2 & 0 & 1 & 20 \\
\hline Material 2 & 4 & 5 & 0 & 18 \\
\hline Material 3 & 1 & 2 & 2 & 15 \\
\hline
\end{tabular}

Table 1: Production cycle requirements

Moreover, the company is making a profit of 32 units on product A in market $\mathrm{M}_{1}$, 31 units in $\mathrm{M}_{2}, 34$ units in $\mathrm{M}_{3}$ and 30 units in $\mathrm{M}_{4}$. In addition, it has incurred a cost of 8 units for its products in $\mathrm{M}_{1}, 12$ units in $\mathrm{M}_{2}, 10$ units in $\mathrm{M}_{3}$ and 7 units in $\mathrm{M}_{4}$. 


\begin{tabular}{|l|c|c|c|}
\hline & A & B & C \\
\hline Profit & $(32,31,34,30)$ & $(33,29,31)$ & $27,25,26)$ \\
\hline Cost & $(8,12,10,7)$ & $(7,9,6)$ & $(9,11,10)$ \\
\hline Output & $(16,19,20,17)$ & $(23,19,21)$ & $(17,15,16)$ \\
\hline No. of employees & $(9,8,10,7)$ & $(8,4,3)$ & $(9,11,10)$ \\
\hline
\end{tabular}

Table 2: Data for markets $A, B$ and $C$

Solution: Let $\mathrm{x}_{1}, \mathrm{x}_{2}, \mathrm{x}_{3}$ be the number of units of products $\mathrm{A}, \mathrm{B}$ and $\mathrm{C}$ respectively. Let $Z_{1}$ denote the profit / cost ratio and $Z_{2}$ be output / employee's ratio.

A bilevel linear fractional programming problem with multi-choice parameters is given by

$(\mathrm{BLFMCP}): \quad \operatorname{Max}_{x_{2}, x_{3}} Z_{1}(x)=\frac{(32,31,34,30)}{(8,12,10,7)} x_{1}+\frac{(33,29,31)}{(7,9,6)} x_{2}+\frac{(27,25,26)}{(9,11,10)} x_{3}$

$$
\operatorname{Max}_{x_{1}} Z_{2}(X)=\frac{(16,19,20,17)}{(9,8,10,7)} x_{1}+\frac{(23,19,21)}{(8,4,3)} x_{2}+\frac{(17,15,16)}{(9,11,10)} x_{3}
$$

subject to

$$
\begin{aligned}
2 x_{1}+x_{3} & \leq 20 \\
4 x_{1}+5 x_{2} & \leq 18 \\
x_{1}+2 x_{2}+2 x_{3} & \leq 15 \\
x_{1}, x_{2}, x_{3} & \geq 0
\end{aligned}
$$

We introduce integer variables $w_{j}(j=1,2,3)$ and $v_{j}(j=1,2,3)$ in the upper level problem and integer variables $z_{j}(j=1,2,3)$ and $y_{j}(j=1,2,3)$ in the lower level problem. Using interpolating polynomials, BLFMCP can be written as (BPPLIP):

$$
\begin{gathered}
\operatorname{Max}_{x_{2}, x_{3}} Z_{1}=\left(\frac{32-\frac{20}{3} w_{1}+\frac{15}{2} w_{1}^{2}-\frac{11}{6} w_{1}^{3}}{8+\frac{26}{3} v_{1}-\frac{11}{2} v_{1}^{2}+\frac{5}{6} v_{1}^{3}}\right) x_{1}+\left(\frac{33-7 w_{2}+3 w_{2}^{2}}{7+\frac{9}{2} v_{2}-\frac{5}{2} v_{2}^{2}}\right) x_{2} \\
+\left(\frac{27+\frac{23}{2} w_{3}+\frac{3}{2} w_{3}^{2}}{9+\frac{7}{2} v_{3}-\frac{3}{2} v_{3}^{2}}\right) x_{3}
\end{gathered}
$$


$\operatorname{Max}_{x_{1}} Z_{2}=\left(\frac{16+\frac{10}{3} z_{1}-\frac{1}{3} z_{1}^{3}}{9-\frac{31}{6} y_{1}+\frac{11}{2} y_{1}^{2}-\frac{4}{3} y_{1}^{3}}\right) x_{1}+\left(\frac{23-7 z_{2}+3 z_{2}^{2}}{8-\frac{11}{2} y_{2}+\frac{3}{2} y_{2}^{2}}\right) x_{2}+\left(\frac{17-\frac{17}{2} z_{3}+\frac{3}{2} z_{3}^{2}}{9+\frac{7}{2} y_{3}-\frac{3}{2} y_{3}^{2}}\right) x_{3}$

subject to constraints (4)

Using Lingo 15.0, solve the upper level problem $\mathrm{Z}_{1}$ and lower level problem $\mathrm{Z}_{2}$, individually subject to the constraints (4).

The solution obtained in this way is Max $\mathrm{Z}_{1}=51.25$ with $\mathrm{x}_{1}=4.5, \mathrm{x}_{2}=0, \mathrm{x}_{3}=$ 5.25 .

Max $\mathrm{Z}_{2}=31.44$ with $\mathrm{x}_{1}=0, \mathrm{x}_{2}=3.6, \mathrm{x}_{3}=3.9$. Using the above data, the fuzzy programming problem FPBLFPP is defined by

(FPBLFPP):

$$
\begin{gathered}
\operatorname{Max} \delta \\
\mu\left(Z_{1}(X)\right) \geq \delta \\
\mu\left(Z_{2}(X)\right) \geq \delta \\
\mu\left(x_{2}\right) \geq \delta \\
\mu\left(x_{3}\right) \geq \delta \\
x_{1}, x_{2}, x_{3} \geq 0 \\
0 \leq w_{1}, z_{1} \leq 3, \quad 0 \leq w_{2}, z_{2} \leq 2,0 \leq w_{3}, z_{3} \leq 2 \\
0 \leq v_{1}, y_{1} \leq 3, \quad 0 \leq v_{2}, y_{2} \leq 2,0 \leq v_{3}, y_{3} \leq 2 \\
w_{j}, z_{j} \in Z^{+} \cup\{0\} ; \quad j=1,2,3, v_{j}, y_{j} \in Z^{+} ; \quad j=1,2,3 ; \delta \in[0,1]
\end{gathered}
$$

It can be rewritten as

(FPBLFPP):

$\operatorname{Max} \delta$

subject to $\mu\left(Z_{1}(X)\right) \geq 51.25 \delta$

$$
\begin{gathered}
\mu\left(Z_{2}(X)\right) \geq 31.44 \delta \\
\frac{3.6-x_{2}}{3.6} \geq \delta \\
\frac{x_{3}-3.5}{1.35} \geq \delta
\end{gathered}
$$




$$
\begin{gathered}
\frac{7.5-x_{3}}{2.25} \geq \delta \\
0 \leq w_{1}, z_{1} \leq 3, \quad 0 \leq w_{2}, z_{2} \leq 2,0 \leq w_{3}, z_{3} \leq 2 \\
0 \leq v_{1}, y_{1} \leq 3, \quad 0 \leq v_{2}, y_{2} \leq 2, \quad 0 \leq v_{3}, y_{3} \leq 2 \\
w_{j}, z_{j} \in Z^{+} \cup\{0\} ; \quad j=1,2,3, v_{j}, y_{j} \in Z^{+} ; \quad j=1,2,3 ; \delta \in[0,1]
\end{gathered}
$$

Thus we have

(FPBLFPP):

$\operatorname{Max} \delta$

$$
\begin{aligned}
& \text { subject to }\left(\frac{32-\frac{20}{3} w_{1}+\frac{15}{2} w_{1}^{2}-\frac{11}{6} w_{1}^{3}}{8+\frac{26}{3} v_{1}-\frac{11}{2} v_{1}^{2}+\frac{5}{6} v_{1}^{3}}\right) x_{1}+\left(\frac{33-7 w_{2}+3 w_{2}^{2}}{7+\frac{9}{2} v_{2}-\frac{5}{2} v_{2}^{2}}\right) x_{2} \\
& +\left(\frac{27+\frac{23}{2} w_{3}+\frac{3}{2} w_{3}^{2}}{9+\frac{7}{2} v_{3}-\frac{3}{2} v_{3}^{2}}\right) x_{3} \geq 51.25 \delta \\
& \left(\frac{16+\frac{10}{3} z_{1}-\frac{1}{3} z_{1}^{3}}{9-\frac{31}{6} y_{1}+\frac{11}{2} y_{1}^{2}-\frac{4}{3} y_{1}^{3}}\right) x_{1}+\left(\frac{23-7 z_{2}+3 z_{2}^{2}}{8-\frac{11}{2} y_{2}+\frac{3}{2} y_{2}^{2}}\right) x_{2}+\left(\frac{17-\frac{17}{2} z_{3}+\frac{3}{2} z_{3}^{2}}{9+\frac{7}{2} y_{3}-\frac{3}{2} y_{3}^{2}}\right) x_{3} \geq 31.44 \delta \\
& x_{2}+3.6 \delta \leq 3.6 \\
& x_{3}+2.25 \delta \leq 7.5 \\
& x_{3}-1.35 \delta \geq 3.9 \\
& x_{1}, x_{2}, x_{3} \geq 0 \\
& 0 \leq w_{1}, z_{1} \leq 3,0 \leq w_{2}, z_{2} \leq 2,0 \leq w_{3}, z_{3} \leq 2,0 \leq v_{1}, y_{1} \leq 3,0 \leq v_{2}, y_{2} \leq 2 \text {, } \\
& 0 \leq v_{3}, y_{3} \leq 2 w_{1}, w_{2}, v_{1}, v_{2}, z_{1}, z_{2}, y_{1}, y_{2} \in Z
\end{aligned}
$$

In solving the above problem using Lingo 15.0, we have Max $\delta=0.7272, \mathrm{x}_{1}=3.27$, $\mathrm{x}_{2}=0.981$ and $\mathrm{x}_{3}=4.88$. The company wants to invest in one product for a single 
market, so that the leader and follower can maximize their profitability ratio and output / employee ratio in that particular market.

Now, for the leader, we have

$$
\begin{aligned}
Z_{1}(X) & =\frac{(32,31,24,30)}{(8,12,10,7)}(3.27)+\frac{(33,29,31)}{(7,9,6)}(0.981)+\frac{(27,25,26)}{(9,11,12)}(4.88) \\
& =(4.258,3.4, \underline{4.286})+(4.714,3.22, \underline{5.167})+(\underline{3}, 2.272,2.6)
\end{aligned}
$$

Again, for the follower, we have

$$
\begin{aligned}
Z_{2}(X) & =\frac{(16,19,20,17)}{(9,8,10,7)}(3.27)+\frac{(23,19,21)}{(8,4,7)}(0.981)+\frac{(17,15,16)}{(9,11,10)}(4.88) \\
& =(1.778,2.375,2, \underline{2.429})+(2.875,4.75, \underline{7})+(\underline{1.889}, 1.364,1.6)
\end{aligned}
$$

From (5) and (6), we observe that the company should invest in market $\mathrm{M}_{4}$ for product $\mathrm{A}$, in market $\mathrm{M}_{3}$ for product $\mathrm{B}$ and in market $\mathrm{M}_{1}$ for product $\mathrm{C}$.

\section{Conclusions}

In this paper, a bilevel linear fractional programming problem is considered in which the cost coefficients of the objective functions at both the levels are of multi-choice. The multi-choice parameters are replaced by interpolating polynomials. The problem is converted into a fuzzy programming problem by defining the membership functions for the leader, the follower and the variables controlled by the leader. A satisfactory solution is obtained after solving this fuzzy programming problem. By using the traditional approach for solving BLFMCP, the size of the problem becomes large and complex. By using the above explained method,

the problem requires less computational work and can be further solved by using software like LINGO.

\section{Acknowledgements}

The authors are thankful to the referees for their valuable suggestions which helped in improving the paper.

\section{References}

[1] Abo Sinna, Mahmoud A. (2001). A bilevel non-linear multi-objective making under fuzziness. Opsearch, 38(5), 484- 495. 
[2] Acharaya, S. and Biswal, M.P. (2015). Application of multi-choice fuzzy linear programming problem to a garment manufacturing company. Journal of Information and Optimization Sciences, 36(6), 569- 593.

[3] Arora, R. and Thirwani, D. (2013). Bilevel capacitated fixed charge transporttation problem. The Electronic International Journal Advanced Modeling and Optimization, 15(3), 645-669. Available at: http://camo.ici.ro/journal/vol15 /v15c6.pdf

[4] Arora, S.R., Malhotra, Neelam and Thirwani, D. (2002). An algorithm for bilevel fractional program when the follower controls few variables. Indian Journal of Pure and Applied Mathematics, 33(2), 227-235.

[5] Atkinson, K., Han, W. and Stewart, D. (2009). Numerical solution of ordinary differential equations. New Jersy: Wiley Interscience.

[6] Bellman, R.E. and Zadeh, L.A. (1970). Decision making in a fuzzy environment. Management Science, 17, 141- 164.

[7] Bialas, W.F. and Karwan, M.H. (1984). Two- level programming. Management Science, 30(8), 1004- 1020.

[8] Calvete, H.I., Gale, C. and Mateo, P. (2008). A new approach for solving linear bilevel problems using genetic algorithms. European Journal of Operational Research, 188(1), 14-28.

[9] Candler, W. And Townsley, R.J. (1982). A linear two- level programming problem. Computers and Operations Research, 9, 59- 76.

[10] Chang, C- T. (2008). Revised multi- choice goal programming. Applied Mathematical Modelling, 32(12), 2587- 2595.

[11] Lee, E.S. and Shih, H.S. (2001). Fuzzy and multilevel decision making: an interactive computational approach. London: Springer- Verlag.

[12] Liao, Chin Nung and Chih, I. Liang (2014). Knowledge management systems selection by multi-choice goal programming. Human Systems Management. 33(1-2), 19-25.

[13] Liao, C-N. (2009). Formulating the multi-segment goal programming. Computers and Industrial Engineering, 56(1), 138-141.

[14] Lin, Yu-Hsien Edward (1994). Multiple choice programming: a state-of-the art review. International Transactions in Operational Research, 1(4), 409421.

[15] Mohamed R.H. (1997). The relationship between goal programming and fuzzy programming. Fuzzy sets and Systems, 89(2), 215- 222.

[16] Pal, B.B. and Moitra, B.N. (2003).A goal programming procedure for solving problems with multiple fuzzy goals using dynamic programming. European Journal of Operational Research, 144, 480- 491.

[17] Sun, Dazhi., Benekohal, Rahim, F. and Waller, S. Travis (2006). Bilevel programming formulation and heuristic solution approach for dynamic traffic signal optimization. Computer-Aided civil and Infrastructure Engineering, 21(5), 321-333. 
[18] Tanaka, H., Okuda, T. and Asai, K. (1974). On fuzzy mathematical programming. Journal of Cybernatics, 3(4), 37- 46.

[19] Yi, P., Cheng, G. and Jiang, L. (2008). A sequential approximate programming strategy for performance measure-based probabilistic structural design optimization. Structural Safety, 30(2), 91-109.

[20] Zimmermann, H.J. (1978). Fuzzy programming and linear programming with several objective functions. Fuzzy Sets and Systems, 1(1), 45-55. 